\title{
Total Quality Management System in an Education Environment: The Case of a Private University in Bahrain
}

\author{
Mahmood A. Akbar ${ }^{1, *}$, Mohd H. Ali ${ }^{2}$ and Syed S. Alam ${ }^{3}$
}

${ }^{1}$ Graduate School of Business, Universiti Kebangsaan Malaysia; ${ }^{2}$ Faculty of Economics and Management, Universiti Kebangsaan Malaysia; ${ }^{3}$ Faculty of Business, Finance and Hospitality, Mahsa University, JIn SP 2, Bandar Saujana Putra, Jenjarom, Selangor, 42610, Malaysia

\begin{abstract}
The study aims to analyze and explain the effectiveness and efficiency of implementing total quality management principles in private educational institutions. The context of the study narrowed down the areas of comparisons to tutorial conducts, student affairs and infrastructure. A detailed analysis of the existing total quality management currently in place at the selected university was duly comprehended. This resulted in finding the flaws/weaknesses in the system of universities in the kingdom of Bahrain generally. Findings through a survey and interview sessions indicated that teachers were not consulted for any changes in curriculum which leads to a lack of cooperation between management and teachers. Another problem in regards to the total quality management implementation was that students perceived the university as not being concerned with maintenance of the premises. Moreover, student affairs/services section was seriously lacking sport facilities, limited training sessions, poor equipment maintenance.
\end{abstract}

Keywords: Total Quality Management, Educational, Bahrain, Quality Management System.

\section{INTRODUCTION}

Quality is not defined only in academic terms but too much scholarly debate has been made on maintaining standards outside the education industry (Green, 1994). The perception of customer, defines quality. Therefore any feature can be perceived as quality by someone but for others it may be just an attribute or nothing. Quality is all about "how a customer perceives your product"? (Mukhopadhyay, 2006). Crosby (1979) defined quality as "conformance to requirement" while according to Juran and Gryna (1980) quality means "fitness for use". Deming (1986) defined quality as "a predictable degree of uniformity and dependability at low cost and suited to the market". Many organizations found that the old definition of quality, "the degree of conformance to a standard", was too narrow. Therefore, they used a new definition of quality in terms of "customer focus". Reason behind this new term was the increase attention and interest of different stakeholders like media, students and government departments in higher educational institutions. This attention and interest leaded institutions to ensure the quality on continuous basis which has also become their major concern. Institutions are giving more attention to quality than ever before but still there is a room for improvement (Gaither, 1998). Governments have established certain criteria in many countries to judge the quality of higher educational institutions. In few developing countries, systems are

*Address correspondence to this author at the School of Business, Universiti Kebangsaan Malaysia, Malaysia; E-mail: Mahmooda.hussain@hotmail.com just made to follow a trend or satisfy the international donors for quality education in the country. These developing countries have not implemented the quality system with its true essence because of which condition of quality is at miserable level. The system of improving education plays a vital role in refining economic situation of a country which ultimately leads to poverty elimination. The overall approach and attention of an organization towards maintaining quality is known as quality framework. This framework provides assurance of quality within the systems of an organization (Baird, 2006). Maintenance of certain quality standards is now becoming legal requirement for universities of many countries across the globe. Universities have assigned separate departments for maintaining and assuring quality of their systems in line legislative authorities of country.

Total quality management requires an organization to evaluate the performance of their employees by processing through a fair methodology and take necessary measures to make them enable for achieving continuous improvement in all the important areas of organization. According to Corrigan (1995), TQM is an approach which focuses on customer driven organizational strategies to achieve highly satisfied customers through the implementation of continuous improvement in processes and products. Kaufman (1992) believed that TQM is providing the requirements of customer's perception.

The term TQM in education was firstly used in 1988 by David Lang for at Mt. Edgecombe High School in Alaska. TQM has gained importance in education field 
which can be evidenced by a bunch of books and articles written on this topic since 1990 (Tucker 1992). To increase the importance of TQM in education, the Association for Supervision and Curriculum Development spent a whole month of November, 1992 to issues its journal "Educational Leadership". Crawford and Shutler (1999) implemented the model of Crosby (1994) in order to suggest a strategy for better implementation of basic TQM principles in education sector. Prajogo and McDermott (2005) stated few basic factors contributing towards the successful implementation of TQM in education sector which were not aligned with the culture of an organization. Companies, who have the culture of continuous learning and welcoming change, implement the changes easily as compare to companies which resist cultural change. All elements of culture should be given attention while implementing quality management which can result in achieving high level of quality management across the organization. Therefore organizations should aim to achieve a culture of quality management which would create ease for company in continuous improvement.

Quality management is not simply a process to achieve efficiency and effectiveness but it is a system of value or practices which forms the foundation for organizational culture. Quality management can be explained as a practice which can be implemented across any type of culture prevailing in company Naor et al. (2008). Different elements of culture can be aligned with the procedures and principles of total quality management for its successful and efficient implementation Prajogo and McDermott (2005).

The procedure of quality management is different from culture adoption as it can be adapted and developed according to the context of an organization (Sila, 2007). Foremost important thing while implementing quality management is change management.

\section{LITERATURE REVIEW}

In many organizations, total quality management is used a management philosophy. Many organizations focus on quality merely to get competitive advantage in terms of productivity, profitability, quality and customer satisfaction (Shafiq, Lasrado, \& Hafeez, 2019). The relationship between quality and educational industry has explained with the help of past studies in literature review. Different studies have supported the claim of TQM's importance in education sector.

\subsection{Quality Avenues}

A company has to pay cost in different ways for providing and maintaining a poor quality. This cost can be in shape of inspections, providing the product or service again and loss of sales due to dissatisfaction. There are other costs which are also related to providing quality but they mostly occur at a specific period of product life cycle. These costs include training of employees and buying latest equipment. The second assumption of TQM is that employee's consensually spend more time for getting trained and understanding the usage of tools. The problems in quality are not merely linked with the functional area and this is the third assumption for total quality management. Fourth assumption for TQM is that the major responsibility for maintaining and implementing quality management lies on top level management who design products and services to satisfy their customers. There is a direct relationship between the system of quality created and applied by top management. Moreover, there is a direct relationship between the ability and skills of employees which increase their productivity through efficient ways of working in high quality working environment (Martin and Bartol, 1998). The quality management or assurance process should develop a learning environment. In this environment learning opportunities, programs content and academic instruments should be parallel to final university objectives (Brucag, 2018).

\subsection{Techniques of TQM}

The advocates and supporters of TQM principles suggested different ways to implement the change brought up by TQM principles. A useful technique for implementing TQM is to calculate the cost which would be saved by maintaining quality. Organization should ensure the right way for completing work and the estimated cost which would be saved by completing the task in rightful manner. The comparison between the cost saved by quality management and cost occurred due to poor quality should be done on regular basis to judge and measure the effectiveness of implementation. Implementation of quality improvement saves significant amount of cost for the company which is appreciated by the concept of quality analysis (Evans and Lindsay, 1996). Training of employees is considered as an important aspect for implementing TQM principles. A company must ensure that the skills and competence of employees should match with skills require for TQM. The concept of benchmarking should 
be used to achieve efficiency among employees. A company should know the areas where it makes profit and where the company is unable to make it. This is a difference between successful and unsuccessful companies which makes it easy to determine the efficiency of organization and its employees.

There are no markets for nonprofit organizations controlled by customers which make it difficult to identify the standards of effectiveness. There is a conflict between the ideas of practitioners and different academicians for the measurement of effectiveness and efficiency of schools. Benchmarking is a concept which should be followed on continuous basis within educational institutions. Benchmarking is comparing the effectiveness of different departments of employees within the organization or with different competing organizations. This benchmarking concept helps the companies in raising their competence level and improving their overall system of quality as compare to their competitors (Kelly, 2006).

Benchmarking makes it clear that the higher standard for performance is a necessary for survival of organization as well as employees McShane and Von Glinow (2006). Moreover, it aims to provide a practical solution of company's problems related to quality of their product and service, compensation to employees, roles and authorities and developing inter and intra department cooperation (Gibson, Ivancevich and Donnelly, 2004).

Benchmarking is mostly used in production companies whereas it is absent in educational sector which raises the question over the quality system of education sector. Schools have their own different and complex ways of measuring the effectiveness of education provided by them. The level of success in examinations, enrolment trends, inspections and other related reports are basic measures of effectiveness. Continuous learning of teachers, quick response of intuitions towards the issues, proactive approach and maintenance of discipline are the important aspects to be measured while checking educational quality of school teachers (Pineda, 2013).

\subsection{Quality as a Measure of Effectiveness in Education}

According to Kelly and Johnson (2002), effectiveness of any organization is its capability of doing anything within specified time. Effectiveness is a planned outcome instead of accidental outcome. Due to its planned nature, the practices which have produced best result for practitioners can be observed and applied. Quality is about doing the task in rightful manner which saves the maximum time and cost without compromising on quality, objectives and aims set for achieving customer's satisfaction (Day, 2018).

Quality of product and quality of service are the two main categories of quality. Quality identifies the important characteristics or features of product or services which can provide maximum satisfaction to customer. Moreover, it provides a view that how flexible and competent operations are required to fulfill the requirements. Service quality refers to providing the service within the set time and courteous behavior (Hitt, Ireland, and Hoskisson, 2005). In higher educational institutions, quality assurance should be the main priority of civil society and government. Expectations for a better performance in the quality of teaching, scientific research and other similar activities, obliges the university managers and administrators to review their strategy (Brucag, 2018).

Quality means the level of brilliance. It means the unique and fundamental character which creates something exclusive and the most excellent of its own kind. (Vertian, 2017) Examined TQM which has been implemented in most of the Saudi universities, but only certain of them act excellence in the acceptance and application procedure. The purpose of their research was to emphasize some Saudi universities that effectively implementing the TQM model can increase a competitive gain over their domestic as well by way of worldwide contestants. The study was based on previous explorations \& results came from the practice of TQM in native universities as well as suggestions to guide the successful quality management adoption. (Wani \& Mehran, 2017) investigated the application of total quality management in advanced teaching institutions. Total quality management is an impression rather than a practice by itself. Therefore, the higher education institutions must scrutinize numerous hurdles sensibly for the effective execution of TQM for attaining continuous perfection and sustainability. This investigation attempt exertions to examine TQM in higher education and structure the literature on Application of TQM in HEl make sure that the requirements of the participants are encountered. Khan et al. (2018) explores the research by using different essential viewpoints to maintain the quality of education. The purpose of this research to examine the total quality management in education: an analysis. The result shows that advanced infrastructure should 
be provided to all the educational institutions, wellskilled management, and the well-trained teaching staff to make total quality management execution success. Not best government assisted institutions, but privately managed academic establishments should be insisted to undertake the philosophy of Total quality management.

\subsection{Quality in Education}

Maxwell (1984) explained that there are six dimensions of quality which are

1. Access: To embrace both geographical expediency and appropriateness of access.

2. Equity: The donation of Education/Training service on the basis of measured rather than any other personal characteristic.

3. Relevance to need: The extent to which the package of service provided for a demarcated population meets their education/training needs.

4. Social acceptability: The extent to which the service meets the potentials of the users, e.g. the interactive and environmental aspects of education/training.

5. Efficiency: The use of resources, money, people, buildings, and equipment.

6. Effectiveness: The balance of education benefits for a discrete person, plus the circumvention of intervention, which is incongruous or useless for the individual person.

TQM in education is most important for the prosperity of families and countries as well. The educational institutions must scrutinize hurdles sensibly for the effective execution of TQM in order to attain continuous perfection and sustainability M.S. Farooq et al., (2007).

\subsection{Educational Policy and Quality in Education}

Once the industrial products are manufactured, you can either buy them or leave. For service, you can look for a better service next time. Defining the quality in terms of education is one of the most challenging tasks. Education does not provide any finished product but it only helps the human being in exploring more knowledge (Mukhopadhyay 2006).

Kalvin \& Malek (2018) investigated the advance management standards in educational infrastructure for the purpose of total quality management in education. This study examined the help of evaluating fresh literature from the internet and other resources by analyzing the fourteen principles of W. Edward Deming's for quality assurance, scrutinizing fourteen principles for the zero-idea defect and quality management. Moreover, this study discussed the quality making plan, quality improvement and quality control. Sadeh and Garkaz (2015) conducted the research on total quality management in higher educational institutions of UK. They examined the quality of educational institutions on different sides of their internal processes. The findings for their study shown that the capacities of TQM norms and essential notions are precarious aspects which reflect the performance of educational institutions. The emphasis of educational policies is on increasing the quality of education which is a crucial matter according to Zgaga (2000). In order to achieve high quality of education, universities should focus on empowering the faculty on different aspects of education. Taylor and Hill (1993) proposed a quality management which emphasizes on training, innovation and availability of resource. Khan, Malik, \& Janjua (2019) studied the impact of TQM practices on the performance of employees working in universities. They also examined the mechanism through which these practices affect the employee performance. Results of their study revealed that the TQM positively and significantly determines employee performance, and the mediating variables of job satisfaction and affective commitment.

\subsection{Educational Change and Quality Management}

It is generally accepted that structures and systems of university should be revised and improved but it is also important to identify the direct improvement. According to West-Burnham and Davies (1994), new management for university should take steps to implement the concept of TQM. They identified several features which are important for educational reforms. These features include information regarding application of TQM in teaching, significance of values, customer focused approach, continuous improvement and techniques to enhance quality.

The TQM focuses on the needs and requirements of all the members of university on continuous basis. Jackson, (2018) explained quality assurance as a set of planned and systematic ways which provide flexibility in meeting the educational requirements of clients. Quality assurance is a proactive approach which tries to sort out the issues. It does not let the 
problem go viral and provide solution before it harms the quality of education. Therefore, quality assurance is a process of finding out the efficiency and effectiveness of the structures and process to achieve the desired results for the satisfaction of customers (i.e students).

Zgaga (2000) explained that students are the real customers in higher educational institutions. Ngware et al. (2006) demonstrated that TQM is an appropriate framework for change and improvement in the school environment. Campatelli et al. (2011) asked 300 Kenyan secondary school teachers about their perceptions of TQM and found that the central educational authorities are not providing the necessary leadership which could promote TQM practices. Asif et al. (2013) developed a simplified model based on the European Foundation for Quality Management autoevaluation model and Six Sigma approach for the implementation of TQM principles for a university's administration. (Alzhrani, Parsa, Shafaq, \& Arshad, 2016) criticized the lack of consensus over critical success factors of TQM in higher education and developing countries.

\subsection{Quality Management Tools}

The goal of quality education is to achieve the excellence in terms of providing and upgrading the skills and adding value to customers or students who attend the university (Feigenbaum 1983). Quality is fitness for educational outcome Juran and Gryna (1980), it is fulfilling the requirement of achieving desired goal by avoiding the flaws and defects in education system Crosby (1979) and also to meet or even exceed the expectations of customer in terms of providing quality (Parasuraman et al. 1985).

It is important to apply the quality management tools before you set the goal to achieve quality assurance. Following are the tools for quality management;

\subsubsection{Strategic Plan}

A proper strategic plan should be formulated to provide a clear vision to university for future. Without this plan, the directions will be ambiguous and the possibility of achieving the desired outcome would be low. This strategic plan should clearly state the mission along with short and long term objectives, policies, roles and rules for assuring quality. Moreover, the plan should define standards to evaluate the policies, procedures and necessary actions to improve the flaws. Policies and procedures along with guidelines should be used as a help to develop the curriculum of the program. It would also be used for identifying the performance of university. The policy should be enforced to follow by all universities, departments and employees to raise the quality standards.

\subsubsection{Indicators of Performance}

Performance indicators are important to identify as they useful to measure the performance of university in terms of quality assurance and providing education. Qualitative and quantitative indicators should be included to correctly find out the performance. Although the quantitative indicators do not provide an in depth detail of issue but they provides a very clear view of the situation. Whereas, qualitative indicators provides the depth required for analysis.

\subsubsection{Admission of Student and its Assessment}

This policy gives non ambiguous information regarding the intake of students and their assessment. In order to achieve the better results, teachers should be given free hand and assessment must be done without any kind of biasness. There are instances where nepotism takes over the meritocracy and people pass exams without having the required skills due to their back up by powerful people. Elimination of nepotism will not only motivate the teachers to maintain meritocracy but it would also motivate the students to work hard for qualifying the admission. Same policies should be formulated for the retention of students without any form of biasness.

\subsubsection{Benchmarking}

Benchmarking can be used as a reference point for improving the quality of existing systems or the development of new system and courses. It provides a clear comparison of university with other local or regional universities in terms of providing quality. In developed countries, too much importance is paid to benchmarking but in developing countries it's difficult because of less approach to technology and information about competitor. But still, benchmarking can set goals for putting university management in direction so that all the members would be focused for the achievement of set benchmark. Garbutt (1996) explored that staff has numerous opportunities to improve their quality by adopting the qualities of industry due to technological advancements. Wood (1991) believes that universities should review the strategic plans including actions, ethics, values, norms and culture of different industry and then implement the possible elements of observation. Foremost important 


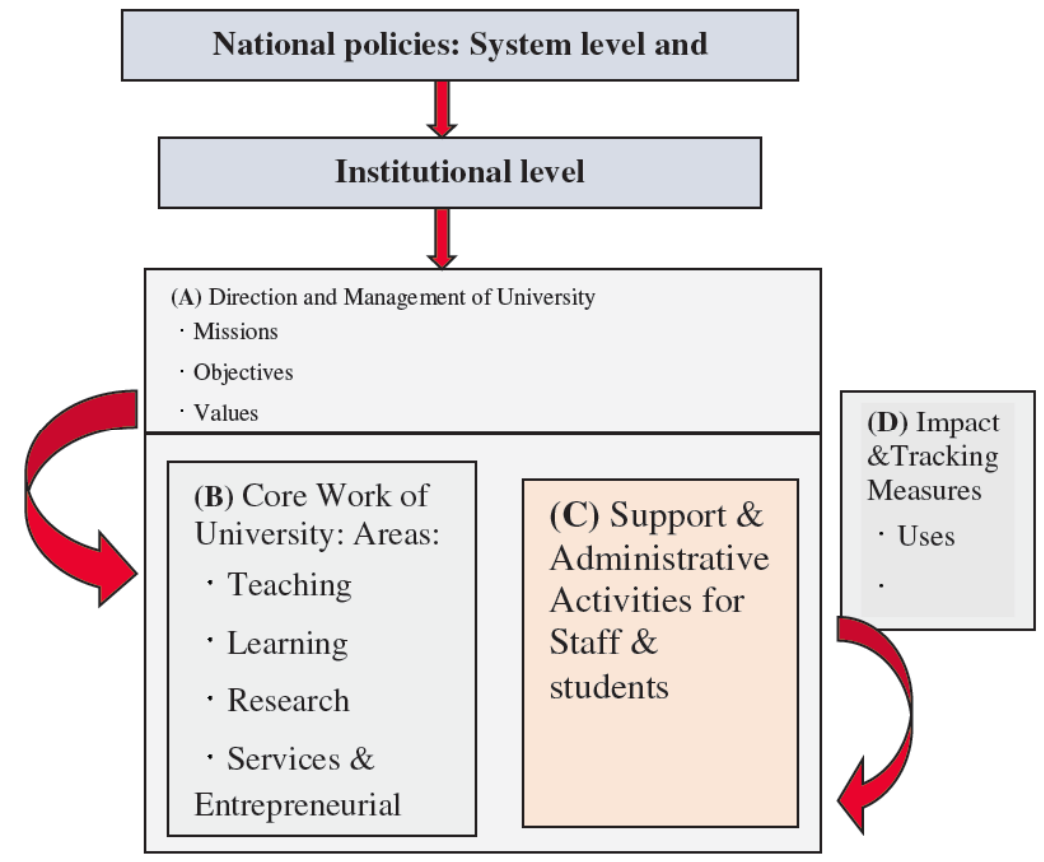

Figure 1: Quality Assurance in Higher Education.

thing is to find out the training methods of different industries. The structure and power of university should be redesigned from hierarchy based organization to team based organization. The culture of team work along with developing a problem solving attitude and self-learning should be embedded in universities. The universities should release decision making power to lower levels and involve employees as much as possible in while making any decision (Harvey \& Newton 2007).

The conceptual framework for assuring quality in higher education is formed on the basis of public policy. Higher education should answerable to public for its policies and structures. According to (Harvey \& Newton 2007) self-evaluation, identification of indicators for performance and peer reviewing has been implemented to achieve the goal of quality assurance in education at university level. To provide a general guideline for this study, a conceptual framework for quality management in higher education is adopted by adapting three conceptual models proposed by Scott (2003), Perellon (2007) and Premfors (1992) depicted in Figure 1.

\section{METHODOLOGY}

\subsection{Research Design and Sampling}

Quantitative and qualitative approaches were applied to gather the data so that accurate and detailed data can be obtained. The primary sources of data collection used for this study were, questionnaires and interviews. For population of 400 sample size should be 196 if confidence interval is 95\% (Saunders, Lewis, \& Thornhill, 2009). The population for our study was 405 so sample was 196 . Therefore, questionnaires were sent to 196 educators but only 174 returned. Moreover the convenience sampling was used. For interview 20 respondents were selected randomly. Talal Abu Ghazaleh University was target of the study.

Both interview and questionnaire approaches were applied during the study. After exploring the already conducted research on the mentioned topic, a questionnaire was designed carefully to get the views of our sample. Then the questionnaires were handed over to specialists for checking the language and style of questions. Totally 6 dimensions were covered through questionnaires along with 37 issues discussed in the final questionnaire passed by specialists. The last dimension of the questionnaire was qualitative and an open ended question regarding total quality management in education. This dimension was judged and analyzed qualitatively.

\subsection{Data Analysis}

ANOVA was used to analyze study variables with age group and work experience. The P-value defines the significance of variable. For every score the difference between the subgroups of independent variable is statistically momentous or not is designated by $p$ value of $F$ parameter. If, the score differences in 
the different categories of independent variable are statistically significant, we can insist the significance of $F$ if $F$ is $<0.05$. $T$ test was to see if there were any significantly different perceptions and opinions of the population with respect to the proposed quality management framework. Data was also analyzed by comparison with the body of literature.

T test and ANOVA were applied by using SPSS. The data obtained through interviews were coded into different categories during the qualitative analysis. Descriptive and inferential coding are two main types of coding. Descriptive code is a short text or summary of data which is later used for higher coding in analysis. Referential coding involves some inference in collected data. The decision regarding coding is dependent on structure of data along with framework and research questions (Keith, 2005). By using this knowledge, the researcher coded the data into 7 different inferential codes which are perceptions of quality, approach to measuring quality, tools for quality management, quality improvement strategies, tracking system for quality, implementation and leadership in the development of the framework.

The method of questionnaire for data collection was very useful and it was formed to provide a range of already existing material. Main focus of questionnaire was on external support, scope, pace and following the protocol. The main reasons of developing the questionnaire were:

1: The first main reason was to get the information regarding the background of independent and dependent variables. It identifies a wide range of indicators in the context of organization.

2: Secondly, this activity will help the researcher for empirical analysis by comparing the results. 3: Third, the questionnaire was constructed to provide data that adequately represent the 'life-world' of each higher education institution. Thus, it provided quick, stable and reliable measurement of the units of analysis.

\section{ANALYSIS}

\subsection{Survey Analysis}

Reliability coefficient Cronbach's Alpha for obtained data (clarity of university, change management, total quality management philosophy adoption university administration, university improvement and the quality of university life) was 0.970 and shown in Table 1 . Educators have a positive attitude towards the implementation of TQM principles with the mean of 126.9 whereas the maximum is 174 . The broadspectrum and most noteworthy verdict of the study was that while educator's characteristics were in all-purpose constructive vis-à-vis quality management in the educational institution, while we experienced the contradictory independent variables as age or years of experience and did not find any significant differences.

Table 1: Cronbach's Alpha Reliability Coefficient

\begin{tabular}{|c|c|c|}
\hline & A & N of items \\
\hline \hline Clarity of university Principles & 0.857 & 6 \\
\hline University administration & 0.886 & 6 \\
\hline University improvement & 0.889 & 6 \\
\hline The quality of university life & 0.589 & 6 \\
\hline Change management & 0.822 & 6 \\
\hline T.Q.M. philosophy adoption & 0.913 & 6 \\
\hline
\end{tabular}

Following is the explanation of demographic variables by using $T$ test and ANOVA for TQM perceptions in university level education.

\subsubsection{Gender in Relation to TQM Perceptions}

T-test explains that there were no major and prominent differences in the perceptions and attitudes of men and women regarding TQM principles. It gives us an understanding that both genders are of same perceptions regarding TQM application in higher education. Gender difference is not an issue in identifying or evaluating the perceptions regarding TQM (Table 2).

\subsubsection{Age Groups in Relation to TQM Perceptions}

ANOVA shows that the difference in perception on the basis of age group is also not significant regarding TQM application. The perception across different ages for TQM in higher education is almost same. Like gender differences, age differences do not play a role in judging the perceptions for TQM implementation.

\subsubsection{Work Experience in Relation to TQM Perceptions}

ANOVA analysis shows that the difference is not significant for TQM perceptions on the basis of educator's experience. Irrespective of work experiences, educators have same perception for TQM 
Table 2: Gender in Relation to TQM Perceptions

\begin{tabular}{|c|c|c|c|c|c|}
\hline & Gender & Mean & Std Deviation & $\mathbf{t}$ & $\mathbf{P}$ \\
\hline \multirow[t]{2}{*}{ Clarity of university principles } & Male & 22,3649 & 4,90059 & -0.144 & 0.556 \\
\hline & Female & 18,0700 & 3,95749 & & \\
\hline \multirow[t]{2}{*}{ University Administration } & Male & 21,6486 & 4,69751 & -0.163 & 0.870 \\
\hline & Female & 21,7700 & 5,03694 & & \\
\hline \multirow[t]{2}{*}{ University improvement } & Male & 22,1351 & 4,68844 & 0.286 & 0.775 \\
\hline & Female & 21,9300 & 4,66938 & & \\
\hline \multirow[t]{2}{*}{ The quality of University life } & Male & 18,8649 & 3,67265 & 1.365 & 0.174 \\
\hline & Female & 18,0700 & 3,95749 & & \\
\hline \multirow[t]{2}{*}{ Change management } & Male & 20,8784 & 4,21333 & -0.404 & 0.687 \\
\hline & Female & 21,1300 & 3,84459 & & \\
\hline \multirow[t]{2}{*}{ TQM Philosophy adoption } & Male & 21,4459 & 4,68499 & 0.172 & 0.864 \\
\hline & Female & 21,3200 & 4,90491 & & \\
\hline
\end{tabular}

in education. Educators who have high experience have the same perception as of educators with low experience.

\subsubsection{Type of Employment in Relation to TQM Perceptions}

There were two statuses of employment according to study. Out of 174 subjects, 165 are working as permanent while 9 are working on hourly basis. T test was applied which found that there is no significant difference in perceptions of educator's between these two groups. Like other groups, they have same perception of totally quality management in higher education. The type of employment of educators does not have any difference on their perception about TQM.

\subsection{Further Studies in Relation to TQM Perceptions}

Out of 174 subjects, 62 were selected to conduct further study and 114 were ignored.

Again, $T$ test was applied and the analysis shows that the difference in perceptions between highly and basic degree holders educators is not significant. The conclusion is that the level of education of educator does not have any impact on his/her perception about TQM in education.

\subsection{Results of the Questionnaire Responses}

New perspectives were drawn from questionnaire responses but most of the answers were aligned with the literature studies. The open ended question was divided into two divisions which are; answers aligned with literature and findings unaligned with literature. The details are shown in Figure 2.

80 to 95 percent respondents agreed to eight statements included in questionnaire for quality improvement strategy. These eight items of questionnaire were $19,17,16,15,14,9$, and 8.

Item 19, referred to 'encouraging teaching staff to develop a subject outline for their students at the beginning of each semester'; item 17 related to 'encouraging staff to be involved in quality management'; item 16 concerned the need to 'encourage good governance, transparency, and accountability to stakeholders'; item 15 related to 'involving stakeholders in the curriculum development'; item 14 referred to 'establishing Quality Assurance Unit/Committee at three levels, including institutional, faculty and department.' item 9 concerned 'comparing the results of self-assessments with external reference points'; and item 8 related to 'disseminating the results of self-assessment of each department through publications'. Items no 10 and 20 had the lowest agreements from respondent which were related to strategy for quality management. Item 20 was recorded 79.8 percent which was about promoting the culture and value of working as a team among teachers and other academic staff while item 10 was recorded $59 \%$ which was related to focusing and evaluating student's knowledge instead of process of institution. 26\% respondents were neutral while $16 \%$ showed their disagreement. It means that the evaluation of student's knowledge along with activities of institution plays a 




Figure 2: Strategy for Quality Improvement.

major role in finding out the quality of education provided by university.

\subsection{Interview Analysis}

The data for interview was obtained from a private university in Kingdom of Bahrain, according to these respondents, it is important to motivate teachers for raise their level of education by pursuing a better and higher level of degree which can enhance their skills and knowledge level. University should help young qualified teachers to continue their studies for Master's or PHD degree in universities of developed countries. Teachers and staff should be provided with training to improve their English speaking skills. Development programs must be created and developed by each department to enhance the performance of its members. University should focus on organizing regular workshops for departments and make it possible for staff and management to attend and learn from those workshops held in country, regionally or internationally. It would help staff to gain confidence and knowledge regarding the meaning full ways of providing education for a better outcome.

According to respondents, training of management and teachers is important to understand the principles of TQM before its implementation. A clear understanding of concepts, principles and methods will help them to better implement TQM for enhancing the level of quality. This response was parallel to the statement in Item no 6 of questionnaire. Respondents believe that universities should allocate funds for the development of research department. Moreover, they should establish proper team to carry our required research and also to motivate teacher so that they can conduct research and publish their own work.

The participants believed that there should be a proper appraisal and evaluation system for staff of 
each department along with incentive plans on the basis of their performance. This will motivate employees to perform better and raise the quality of education. The criterion of promoting any staff member is ambiguous which needs to be structured properly to gain their confidence. According to respondents, the evaluation of management is more important than the evaluation of student's knowledge which should also be evaluated.

Following are the responses of interview sessions which are mostly aligned with the literature review. The unaligned responses are not in agreement but still provide a substantial thought to generate recommendations.

\section{RESULTS AND FINDINGS}

The few answers with agreement are expressed below so that the results would be easy to understand

\subsection{Answers in Agreement with the Literature Review}

Answers of the open question suggested agreement of the respondents to the theory testaments:

1. Drastic changes should be initiated properly for applying the TQM in education and these changes mainly include:

- Facilities and equipment

- Manager selection

- Curriculum and syllabus

- Book writing.

2. By following the procedures of TQM, the relation between different stake holders can be developed which will aid to improve quality.

3. Importance should be given to cooperation of all stakeholders.

\subsection{Findings}

According to findings, implementation of TQM is the most important element of educational reform. The TQM require a drastic change which can be implemented by support and acceptance of educators. The implementation of TQM will lead to develop an environment of mutual respect, honesty, trust, confidence and team work. The research also found that educators need to be trained for implementing
TQM as they are currently untrained. The success of TQM will be achieved through mutual efforts as a team along with involving important stakeholders in decision making. To achieve this, change in behavior of educators as well as society is required. Higher education service providers are making serious efforts to bring the quality but the resistance of aged employees of old methodology is biggest hurdle in achieving desired goals.

1: Initiation of following changes is required:

- $\quad$ The equipment and facilities provided in campus should be solely in the hand of director who is actually a source of motivation and empowerment for teachers.

- Team spirit needs to be developed.

- Stakeholders with strong socio-economic background can play a role in administration. This would help in defining a single direction and all the forces working on the same page. An inspirational leadership can help the people in adapting drastic change to implement TQM.

2: Criticisms regarding selection of directors are addressed as:

- $\quad$ No proper structure for conducting an interview.

- Ignoring the level of qualification of applicants.

- $\quad$ Everyone has its agreement on the principles of TQM but there is ambiguity regarding who will take the responsibility of implementing total quality management.

- TQM in education refers to evaluation of each department. It is important to note that these evaluations must be controlled by centralized administration otherwise desired goals will not be achieved.

- $\quad$ Educators having the motivation and moralities to promote education should only be hired.

- Improved facilities and equipment are needed to improve the efficiency and effectiveness of staff or students.

\section{CONCLUSION}

The study is an effort to examine and analyze the opinions, perceptions and ideas about total quality 
management practices in education sector. The general findings reflect that teachers are very positive about achieving the desired results of improving quality through TQM. They believe that the desired results can be achieved by the implementing TQM in education and overall system of university can be enhanced through TQM philosophy. Hence, the research used both the T-test and the ANOVA and did not find any significant differences in the variables question with respect to their experience, education level and gender. One finding of the study was about the negative opinion of staff related to TQM. Staff provides negative ideas and feedback for TQM practices among different dimensions except with the adoption of basic TQM philosophy.

The study revealed that staff of educational institutions is having lack of training in proving quality education and continuously improving their skills to cope up with the latest knowledge and tools. The staff in administration department is facing the same issue of lack of training which has decreased their productivity especially when it comes to implement a change. Along with this, institutes have incomplete information about behaviors and attitudes of consumers which makes them more vulnerable. Mostly, educational institutions do not know about the requirements and needs of their customers, therefore they are unable to satisfy them. The knowledge regarding consumer needs and requirements can help universities to better understand the required changes which would lead them towards customer satisfaction. Total quality management must be used in universities as a tool for continuous improvement by imaging the students as customers and satisfy their requirements. The study also showed that the university lack proper mechanism for evaluation and promotion of staff. The staff is promoted without any clear method of appraisal and many members of staff have faced nepotism on promotion which dissatisfied them. There should be a proper appraisal and promotion system in justifying the performance of employees and keep them motivated.

Currently, universities are neglecting many important issues related to quality but they have mainly emphasized on roles of teachers. The proper training of staff with continuous learning, understanding the behaviors or needs of consumer, targeting customer satisfaction, bringing innovation in skills and processes are the main areas that could help universities and educators to explore things in a different way.
According to findings, the implementation of total quality management principles at university level is insufficient as this implementation has the potential to improve several areas which are; students behaviors, training of educators, overall management and administration and a two way meaningful communication with all stakeholders for getting a proper feedback.

Organizations have culture of continuous learning are most suitable in applying total quality management concepts. The process of learning is elements which makes it suitable for improvement in quality. Achieving employee satisfaction is one of the most important factors in raising the quality of system. A satisfied employee will work with positive attitude and improve his or her skills continuously in order to achieve better results for himself as well for the institution. A satisfied employee will continuously adapt and accept changes to improve quality. In order to improve the efficiency of the university's educational services, there are vital changes that must take place. A method of administration that has shown can change things is TQM. As such, TQM should be incorporated cohesively into the organization and empowering staff in practicing and enhancing the TQM philosophy will greatly propel the organization toward future progress.

Firstly this study will provide valuable information for the next generation of Talal Abu- Gazalah researchers who may be interested in quality assurance issues. Secondly, it will inform and provide guidance for decision-makers and policy planners both at university and national levels, especially the Accreditation Committee of Bahrain and other relevant authorities and organizations. Third, it may in turn, be scaled up for other Bahraini higher education institutions if the research outcomes are perceived as relevant to their contexts. Moreover, the findings of this research will provide a valuable contribution to the development, and enhancement of quality assurance in Talal AbuGazalah higher education through various means. This study has two major limitations; first of all this study is country specific (i.e Bahrain) and other limitation is that the study has used only few variables for TQM measurement. Therefore future studies can replicate this study by using new variables or focusing any other industry except education.

\section{REFERENCES}

Alzhrani, Khadijah Mohammed, et al. (2016) "TQM in Educational Institutes of Saudia Arab." Journal of Institutional TQM 9 (2), 19-38. 
Asif, M., Awan, M. U., Khan, M. K., \& Ahmad, N. (2013). A model for total quality management in higher education. Quality \& Quantity, 47(4), 1883-1904. https://doi.org/10.1007/s11135-011-9632-9

Baird, G. (2006). Pervalence of disorders of the autism spectrum in a population cohort of children in South Thames: the Special Needs Autism Project (SNAP). Lancet, 368, 179-181. https://doi.org/10.1016/S0140-6736(06)69041-7

Bruçaj, S. (2019). Quality Management in Higher Education; Challenges of Private Universities in Albania. European Journal of Education, 1(3), 194-202.

Campatelli, G., Citti, P., \& Meneghin, A. (2011). Development of a simplified approach based on the EFQM model and Six Sigma for the implementation of TQM principles in a university administration. Total Quality Management \& Business Excellence, 22(7), 691-704. https://doi.org/10.1080/14783363.2011.585755

Claude Ah-Teck, J., \& E. Starr, K. (2014). Total Quality Management in Mauritian education and principals' decision-making for school improvement: "Driven" or "informed" by data?. Journal of Educational Administration, 52(6), 833-849.

https://doi.org/10.1108/JEA-06-2012-0075

Crosby, P. B. (1979) Quality Is Free. McGrawHill, New York.

Crawford, L. E., \& Shutler, P. (1999). Total quality management in education: problems and issues for the classroom teacher. International Journal of Educational Management, 13(2), 6773.

https://doi.org/10.1108/09513549910261122

Corrigan, J. (1995) The art of TQM. Quality Progress 28, 61-64.

Day, D. (2018). The Quality Assurance of Higher Education from the Perspective of Professional, Statutory and Regulatory Bodies (PSRBs). Handbook of Quality Assurance for University Teaching. https://doi.org/10.4324/9781315187518-12

Deming, W. E. (1986) Out of Crisis. Cambridge University Press, Cambridge.

Farooq, M. S., Akhtar, M. S., Ullah, S. Z., \& Memon, R. A. (2007). Application of Total Quality Management in Education. Online Submission, 3(2), 87-97.

Feigenbaum, A. V. (1983) Total Quality Control. McGraw Hill, New York.

Gaither, G. H. (1998). Quality assurance in higher education: An international perspective. Jossey-Bass Publishers.

Garbutt, S. (1996). The transfer of TQM from industry to education. Education+ Training, 38(7), 16-22. https://doi.org/10.1108/00400919610130736

Gibson, I.D., Ivancevich, J., and Donnelly, J. (2004) Organizations: Behaviour, Structure and process, McGraw-Hill Companies Inc, Boston.

Green, D. (1994). What Is Quality in Higher Education?. Taylor \& Francis, 1900 Frost Road, Bristol, PA 19007-1598.

Harvey, L., \& Green, D. (1993). Defining quality. Assessment \& evaluation in higher education, 18(1), 9-34. https://doi.org/10.1080/0260293930180102

Harvey, L., \& Newton, J. (2007). Transforming quality evaluation: moving on. In Quality assurance in higher education (pp. 225-245). Springer, Dordrecht. https://doi.org/10.1007/978-1-4020-6012-0 9

Hitt, M. A., Ireland, R. D., \& Hoskisson, R. E. (2012). Strategic management cases: competitiveness and globalization. Cengage Learning.

Jackson, N. (2018). Engaging and changing higher education through brokerage. Routledge. https://doi.org/10.4324/9781315194066

Kalvin, K. \& A. Tabmi M. (2018) The evaluation of Total Quality Management in Institutions of UK. Journal of Education Society 7 (2), 17-34.
Kaufman, R. (1992). The challenge of Total Quality Management in education. International Journal of Educational Reform, 1(2), 149-165. https://doi.org/10.1177/105678799200100206

Kelly, C. D. (2006). Replicating empirical research in behavioral ecology: how and why it should be done but rarely ever is. The Quarterly review of biology, 81(3), 221-236. https://doi.org/10.1086/506236

Kelly, W. E., \& Johnson, J. L. (2005). Time Use Efficiency and the Five-Factor Model of Personality. Education, 125(3).

Khan, Uzma Rasool, et al. (2018) "Total Quality Management in Education." Dalam International Journal of Science and Business 2 (2), 182-197.

Khan, M. N., Malik, S. A., \& Janjua, S. Y. (2019). Total Quality Management practices and work-related er education institutions in Pakistan. International Journal of Quality \& Reliability Management. https://doi.org/10.1108/IJQRM-04-2018-0097

Evans, J. R., \& Lindsay, W. M. C. (2002). The management and control of quality (No. 658.562 Ev157i Ej. 13 017629). South Western,

Mukhopadhyay, M. (2016). Quality Management in Higher Education. SAGE Publications India.

Martin, D. C., \& Bartol, K. M. (1998). Performance appraisal: Maintaining system effectiveness. Public Personnel Management, 27(2), 223-230. https://doi.org/10.1177/009102609802700208

Maxwell, R. J. (1984). Quality assessment in health. British medical journal (Clinical research ed.), 288(6428), 1470. https://doi.org/10.1136/bmj.288.6428.1470

Parasuraman, A., Zeithaml, V. A., \& Berry, L. L. (1985). A conceptual model of service quality and its implications for future research. Journal of marketing, 49(4), 41-50. https://doi.org/10.1177/002224298504900403

Perellon, J. F. (2007). Analysing quality assurance in higher education: proposals for a conceptual framework and methodological implications. In Quality Assurance in Higher Education, 155-178. https://doi.org/10.1007/978-1-4020-6012-0_6

Pineda, A. P. M. (2013). Total quality management in educational institutions: Influences on customer satisfaction. Asian Journal of Management Sciences and Education, 2(3).

Prajogo, Daniel I., and Christopher M. McDermott. (2005) Developing an institutional framework for rewarding excellence in teaching: a case study. Quality Assurance in Education, 6 (2), 97-105. https://doi.org/10.1108/09684889810205750

Premfors, R. (1992). Knowledge, power, and democracy: Lindblom, critical theory, and postmodernism. Knowledge, Technology \& Policy, 5(2), 77-93. https://doi.org/10.1007/BF02692807

Punch, K. F. (2013). Introduction to social research: Quantitative and qualitative approaches. sage.

Sadeh, E., \& Garkaz, M. (2015). Explaining the mediating role of service quality between quality management enablers and students' satisfaction in higher education institutes: the perception of managers. Total Quality Management \& Business Excellence, 26(11-12), 1335-1356. https://doi.org/10.1080/14783363.2014.931065

Saunders, M., Lewis , P., \& Thornhill, A. (2009). Research Methods for Business Students (5th ed.). England: Pearson Education Limited.

Scott, D. (2003). Culture in political theory. Political theory, 31(1), $92-$ 115. https://doi.org/10.1177/0090591702239440

Shafiq, M., Lasrado, F., \& Hafeez, K. (2019). The effect of TQM on organisational performance: empirical evidence from the 
textile sector of a developing country using SEM. Total Quality Management \& Business Excellence, 30(1-2), 31-52. https://doi.org/10.1080/14783363.2017.1283211

Sila, I. (2007). Examining the effects of contextual factors on TQM and performance through the lens of organizational theories: An empirical study. Journal of Operations management, 25(1), 83-109. https://doi.org/10.1016/j.jom.2006.02.003

Taylor, A., and Frances H. (1993). Quality management in education. Quality Assurance in Education, 1 (1), 21-28. https://doi.org/10.1108/09684889310040712

Veteran, P. (2017). Total quality management: A study from the perspective of higher education Institutions. Le travail Humain. 78 (9), 89-103.

Von Glinow, M. A., \& McShane, S. L. (2006). Organizational Behavior: Emerging Realities for the Workplace Revolution.

Waithanji Ngware, M., Kuria Wamukuru, D., \& Onyango Odebero, S. (2006). Total quality management in secondary schools in
Kenya: extent of practice. Quality assurance in Education, 14(4), 339-362.

https://doi.org/10.1108/09684880610703947

Wani, I. A. \& Hakim K. M. (2017). A model for total quality management in higher education. Quality \& Quantity Measures. 47(4), 17-44.

West-Burnham, J., \& Davies, B. (1994). Quality Management as a Response to Educational Change.

Wood, D. J. (1991). Corporate social performance revisited. Academy of management review, 16(4), 691-718. https://doi.org/10.5465/amr.1991.4279616

Zeithaml, V. A., Parasuraman, A., Berry, L. L., \& Berry, L. L. (1990). Delivering quality service: Balancing customer perceptions and expectations. Simon and Schuster.

Zgaga, P. (2009). Higher Education and Citizenship:'the full range of purposes'. European educational research journal, 8(2), 175188. https://doi.org/10.2304/eerj.2009.8.2.175

DOI: https://doi.org/10.6000/1929-7092.2019.08.62

(c) 2019 Kamaludin and Zakaria; Licensee Lifescience Global.

This is an open access article licensed under the terms of the Creative Commons Attribution Non-Commercial License (http://creativecommons.org/licenses/by-nc/3.0/) which permits unrestricted, non-commercial use, distribution and reproduction in any medium, provided the work is properly cited. 